\title{
Raising the Bar: An Approach to Reviewing and Revising Standards for Professional Achievement for Library Faculty
}

\section{Edward F. Lener, Bruce Pencek, and Susan Ariew}

The committee revising the retention, promotion, and continued appointment policy in the Virginia Tech libraries took a broad view of its task in articulating its goal, gathering information from internal and external sources, allocating drafting responsibilities, and winning support. The committee's work revealed an unexpected need and led to an explicit affirmation of professional obligations of librarians to one another. Thus, adoption of the new policy and the principles it embodied became a lever for changes in the organizational culture.

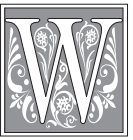

hen a college or university seeks to raise promotion and tenure standards for academic faculty, where do its professional employees fit? How can they affect the standards under which they will be judged? For librarians, the nature and effects of higher retention, promotion, and tenure (RPT) standards will depend not only on whether they have faculty status, but also on the nature of that status: librarians who are entirely integrated into the academic faculty may have different opportunities to affect RPT standards than librarians whose institutions distinguish among classes of faculty. ${ }^{1}$ Naturally, librarians who are professional employees without faculty status face yet another set of issues.
RPT standards reflect the very core of how one's professional contributions are assessed and valued. They also have important career implications. "Good" standards balance the potential tensions among the needs of the institution, the profession, and the individual. When drafting standards or making revisions, it is often a challenge to win assent from all parties due to the complexities involved. Making policy changes in a short time can prove especially problematic-and provides an opportunity. This article describes major elements of a successful revision process pursued in 2002 at Virginia Tech. The approaches described here may inform difficult deliberations well beyond one library and university.

Edward Lener is College Librarian for the Sciences at the University Libraries of Virginia Tech; e-mail: lener@vt.edu. Bruce Pencek is College Librarian for the Social Sciences; e-mail: bpencek@vt.edu. Susan Ariew is College Librarian for Education and Human Development; e-mail: saa@vt.edu. All were members of the Faculty Affairs Committee that addressed the issues presented here. 
The committee charged with rewriting RPT standards and procedures for library faculty took several lines of action to create a document that satisfied both a university-wide mandate and the interests of the librarians. Each approach brought its own set of benefits. An internal needs assessment provided valuable clarification of faculty concerns at any early stage. Comparative analysis of policies from benchmark libraries yielded examples of well-crafted principles, practices, and language. A fast-paced drafting process characterized by individual authorship with collective review fostered innovative thinking and avoided abstraction. Finally, a conscious strategy of consensus-building and open participation led to broader confidence and support among the library faculty as a whole and ultimately resulted in a better document. ${ }^{2}$ These new standards were implemented within a few months of their adoption as part of the annual cycle of promotion and continued appointment reviews.

\section{Library Faculty Status}

The "general faculty" at Virginia Tech comprises several classes, each with its own specific role and expectations. Collegiate (i.e., teaching) faculty make up by far the largest single group. In recognition of the different nature of their positions and responsibilities as "extra-collegiate faculty," librarians are eligible for "continued appointment" and/or promotion through a process that parallels that used for teaching faculty, on the recommendation of a separate University Promotion and Continued Appointment Committee for Extra-Collegiate Faculty. The continued appointment track for librarians confers comparable benefits such as protection of academic freedom and job security. (Prior to 1983, library faculty were awarded tenure under the same rules as collegiate faculty. Those originally granted that status retain it.) Teaching and library faculty also participate on equal terms in university governance.

Members of the Virginia Tech library faculty hold the conventional academic ranks of instructor, assistant professor, associate professor, and (full) professor. In the University Libraries, instructors are on an "up or out" track: they must pursue both promotion and continued appointment. Assistant professors who have received continued appointment are encouraged, but not obliged, to seek further promotion.

Promotion and tenure policies for collegiate faculty are spelled out in great detail in the university's Faculty Handbook, with more limited guidelines provided for the extra-collegiate faculties. ${ }^{3}$ The handbook explicitly acknowledges that library faculty promotion and continued appointment deliberations are governed by a separate document, Procedures on Promotion and Continued Appointment: University Libraries, developed by the Library Faculty Association (LFA) and the dean of libraries, the revision of which is the focus of this article.

\section{Mandate}

At Virginia Tech the impetus to review standards for promotion and continued appointment of librarians began in late 2001, when a university-level ad hoc committee on promotion and tenure issued a report that recommended further strengthening existing standards and establishing a more consistent set of procedures across all colleges and departments. The report emphasized the research and scholarship component of the university's academic standards, with comparatively little mention of the areas of teaching, service, and outreach. These recommendations reflected the university's goal to become one of the top thirty American research universities (as ranked by National 
Science Foundation measures of research funding) by $2010 .^{4}$

Shortly after the issuance of the report, the university provost sent a directive to all academic units strongly supporting its recommendations. The letter requested that all units review their standards accordingly and seek to "explicitly delineate appropriate measures or indicators of successful outcomes with respect to research, teaching, and outreach and to ensure fair and equitable treatment of all faculty." ${ }^{5}$ All colleges, the University Libraries, and the extension service were asked to prepare reports, due in approximately four months' time, addressing the recommendations of the university ad hoc committee's report and describing how their respective units had implemented them.

In early February 2002, the provost's charge was referred to the library's Faculty Affairs Committee (FAC), an elected, standing committee of the LFA. LFA is the formal representative body of the library faculty, comprising all librarians, including department heads, below the dean and associate dean.

Fortuitously, the 2001-2002 FAC brought a wide mix of experiences and perspectives to the task. Members varied in rank and degree of seniority, with one full professor, one associate professor, and three assistant professors. With one exception, all committee members had worked in the University Libraries six or more years and had earned continued appointment. Moreover, members were familiar with teaching faculty norms at Virginia Tech and elsewhere concerning promotion and tenure through participation in university governance and other interactions.

\section{Process}

\section{Step One. Gauging Librarian Sentiments}

Although selected elements and language had been modified and updated from time to time during periodic reviews, the existing Promotion and Continued Appointment (P\&CA) document for the University Libraries had not been subject to any extensive revision since 1989 . The FAC began its task by conducting an internal needs assessment using a Webbased questionnaire. (See appendix I.) This proved to be a simple and effective way to gather key background data. In addition to its intended purpose, the survey process provided less tangible, but valuable, benefits. Cajoling faculty to respond to the survey helped sensitize librarians to the reasons behind the review. Moreover, the responses gave the committee a sense of the problems they might encounter in achieving consensus, both within the committee and across the library.

The first section of the survey presented the primary recommendations of the university Ad Hoc Committee on Promotion and Tenure, requesting feedback about how the University Libraries' P\&CA guidelines could best reflect those recommendations. Open-ended questions asked librarians their views regarding research as a P\&CA criterion, how to ensure that P\&CA expectations and standards be communicated fairly and effectively, and how best to implement measures of successful outcomes. The second section asked for LFA members' comments and recommendations about the strengths, weaknesses, and ambiguities of the current P\&CA policy and the relationship of the guidelines to the library's strategic plan.

In a final section included for statistical purposes, respondents could indicate current rank, years of service, years of professional experience, and whether they had ever served on the library's Promotion and Continued Appointment Committee, as those variables might affect the respondents' views. The FAC solicited participation in the survey through multiple channels. Although the nature of 
questions made for a somewhat lengthy survey, the committee emphasized to participants that they needed to complete only those most salient to them. Aside from access controls to prevent anyone from completing the questionnaire more than once, the survey was conducted anonymously. Results, including comments, were compiled instantly and could be viewed online.

Out of thirty-five librarians, eighteen responded. The response rate was slightly higher among those at the instructor and assistant professor rank than from those at associate professor or above. Nine respondents indicated having sixteen or more years of professional experience and six indicated they had served on the library's P\&CA Committee in the past.

As expected, the responses varied a great deal. Answers to individual questions varied from a simple "seems OK" to lengthy discourses. The most frequently expressed concern was that the FAC might try to make radical changes to the standards without seeking adequate input prior to a vote of the LFA membership. Several responses emphasized that, regardless of what the university chose to do, it was very important for the library faculty to have standards that would suitably reflect the nature of the profession and the needs of the University Libraries.

Despite a general desire to maintain the status quo, many of the respondents identified aspects they believed needed improvement. These provided the committee points of departure for its deliberations. For example, one respondent said, "Our procedures for promotion and continued appointment do not communicate 'expectations' very explicitly in terms of measures or indicators. The language right now is vague and needs to be clarified in terms of what candidates need to do." Another asked for inclusion of a checklist and a timetable, especially for junior faculty and new hires.

\section{Step Two. Comparing Local Practices with Other Institutions' Documents}

The FAC felt a commitment from the start to use comparative analysis and to adapt best practices from other large academic libraries. The committee also made reference to the model statement of the ACRL Academic Status Committee regarding promotion and tenure issues. ${ }^{6}$ Thus, at the same time that it was gathering local opinions, the FAC began looking at the promotion and tenure policies of peer institutions (as identified by SCHEV, the State Council of Higher Education for Virginia) and of research universities ranked 21 to 30 in 2000 by NSF, a total of thirty-one universities after duplicate cases were excluded.?

The committee created a spreadsheet on which to compile relevant information. (See appendix II.) This "peers and betters" list included each university's SCHEV or NSF status, whether it was a land-grant institution, whether it granted tenure or some equivalent to librarians, the ranks librarians held, primary criteria for promotion and/or tenure, level of professional development support (e.g., formalized mentoring, research funding, sabbaticals), and URLs for their promotion and tenure documentation. Separate fields were available for annotations about library policies and noteworthy university characteristics. Seeking to put its comparisons on a common footing, the committee soon added additional columns for 2000 Association of Research Libraries data, including overall rank, professional and staff sizes, and enrollment. ${ }^{8}$

Each committee member was assigned six or seven institutions to investigate. The availability of online promotion and tenure documents at many institutions facilitated rapid data collection and provided 
the primary source of information. Some online policies, however, were difficult to interpret with confidence insofar as apparently relevant documents were password protected. When policies regarding librarian faculty status or tenure options were unclear, position announcements often provided some clarification. Committee members also e-mailed requests for additional information when needed.

Policy language varied a great deal across institutions and was often replete with local terminology. Librarian ranks and titles, for example, were not consistent, making comparisons difficult. Furthermore, some documentation did not fully define the classifications used, requiring reference instead to general faculty handbooks or other related materials for the institution. Finally, not all of the universities investigated accord faculty status or tenure to librarians.

\section{Step Three. Analyzing Collected Data}

During the analysis phase, the FAC formed a common idea about what principles any new promotion and continued appointment standards should embody. In particular, the committee sought characteristics that would make the document equitable and rigorous in substance as well as user oriented (to P\&CA committees, to library and university administrators, and to candidates). Members shared the results of the internal survey and the comparative analysis by e-mail and in weekly meetings. Face-to-face conversation generally proved more efficient, more collegial, and less burdensome than e-mail, given the tight deadlines and the sensitive nature of the issues under discussion.

As the committee reviewed policies from libraries on its "peers and betters" list, it struggled with determining what characterized appropriate criteria with regard to local needs. In contrast with institutions such as North Carolina State University (a traditional benchmark and target for Virginia Tech's ambitions), the gap between Virginia Tech's current NSF ranking and its ARL standings is quite broad by any standard. Most notably, Virginia Tech has the smallest professional staff of any ARL library in the United States. ${ }^{9}$ Despite the university's aspirations to climb further in the NSF rankings, the committee could not assume that Virginia Tech would invest heavily enough in additional resources, especially personnel, to raise the University Libraries to comparable levels in the ARL rankings.

Absent a sizeable infusion of resources, blindly ratcheting up P\&CA standards would have been unrealistic institutionally and would have drawn the wrath of many members of the LFA. This was especially true regarding higher expectations of what the provost's mandate called "research productivity." Survey respondents expressed concern that already thinly stretched librarians could be forced to reduce their efforts to provide high-quality services to the academic faculty and students in order to make the time to meet a new quota of publications. Maintaining an appropriate balance among the roles of scholarship, teaching, and service was a key issue facing the committee. The 1998 ACRL report Academic Librarianship and the Redefining Scholarship Project addressed some of these concerns and provided a helpful look at the diverse roles that librarians now fill. ${ }^{10}$ Given both the general satisfaction with the basic standards and processes already in place and the overall compatibility of the existing procedures with practices elsewhere, the FAC decided to retain and better codify much of the substance of the existing P\&CA document while extensively revising the form and presentation.

This process of developing a shared understanding of the ends, available means, 
and rationales facilitated frank, productive discussion in the committee during the drafting phase. In the end, the FAC chose not to base its new document on any a priori model or institution. Rather, discussion of the needs assessment survey and other libraries' promotion and tenure materials led to a general picture of desirable enhancements that the committee sought to incorporate, including:

- an introductory statement of underlying principles (inspired by Duke's document) to guide the interpretation and application of the document;

- an acknowledgment of the responsibilities of the senior librarians and supervisors to encourage the professional growth of faculty;

- a clearer account of the sequence of review events;

- an increased level of detail for review criteria and standards;

- the elimination of inconsistencies and ambiguities wherever possible, including a stricter separation of the rules from advisory and situation-specific statements.

\section{Step Four. Drafting}

The FAC soon adopted a holistic view of its project rather than a merely incremental one. The committee recognized that the old P\&CA documentation was largely written from an insider's point of view - that of the library's experienced administrators and senior faculty for whom the procedures were second nature. To facilitate its conversion into a policy that would be clear and intelligible to all involved, two members took the initiative to lay out structural changes in the document. After discussion, early designs with rigorous parallelism for the roles of candidates, committees, and administrators yielded to a more modest, sequential format intended to simplify access to often-complex procedural information.
This initial method of individual drafting and collective, highly discursive revision set a pattern. Armed with internal advice, an appropriate set of external best practices, and consensus on the shape of the new version, members of the committee singly or in pairs took responsibility for reworking sections of the existing document and crafting the new portions that were envisioned. Members modified and incorporated language from exemplary documents they found elsewhere. Citations to sources for proposed changes, often with rationales, queries, observations, and other discussion items, also were included as color-coded annotations in the files of the section drafts. At the next meeting the committee hammered out consensus language. Meeting frequently (and often on short notice), the committee developed a complete draft of the new model document ready for presentation to the LFA in just over five weeks.

\section{Step Five. Achieving Consensus}

Discussions within the FAC were intense, but not personalized. Two factors were vital to making the revision process productive rather than incendiary. First, as mentioned, members went into the drafting with a shared understanding of their goal and of the general means to its realization. Second, they consciously reminded themselves that they were collective, not individual, authors. These strategies defused tension and reduced the tendency for the drafters to become too firmly entrenched as advocates for any proposed text.

The committee saw that the next crucial challenge would be getting the rest of the library faculty to carefully study and compare the existing document with the draft proposal and to recommend changes and revisions. From the outset, committee members had updated colleagues and solicited their opinions through the survey, progress reports at monthly LFA 
meetings, and informal private communications. When the first complete draft of the new P\&CA document was ready for broader discussion in late April 2002, the FAC posted it on the LFA Web site and held two public forums with the library faculty. Throughout this period, the committee emphasized that the document was still in draft form and that the forums were working meetings to incorporate suggestions and changes.

At each forum, the committee, led by its chair, provided an overview of its research and reasoning before inviting candid, section-by-section discussion of the draft. Librarians of all ranks and functions were present and raised salient questions and points for discussion. Although not LFA members, the dean and associate dean of libraries also were invited and each attended a forum. Their participation was symbolically as well as practically advantageous, given the centrality of the library administration to acceptance of the new document and implementation of its principles.

The public forums provided valuable input to the committee as well as helped to build awareness and support. The FAC then worked to reconcile and incorporate suggested changes and corrections into a revised version. A longtime LFA member outside the committee volunteered to proofread and edit the standards for stylistic consistency before issuance of a revised draft. Finally, the LFA held a "first reading" at the regular monthly meeting of the proposed new Procedures on Promotion and Continued Appointment with further discussion and a nonbinding vote. The next month's LFA meeting included a "second reading" and a final, unanimous vote of approval.

\section{Outcomes}

Although seeking to increase the level of specificity in the new document, the committee avoided narrow checklists or quotas. Rather, its goal was to articulate rational, objective principles and processes that had the flexibility to accommodate individual circumstances and differences. The new document incorporated and transcended the requirements of the provost's original mandate, notably:

- The document became more userfriendly, with events described in a logical sequence and a timetable added.

- The spirit of the document changed, with professional growth and the common good emphasized as the goals of the promotion and continued appointment processes and deliberativeness and fairness emphasized among the means.

- Faculty ranks and professional responsibilities were better defined, with clearer descriptions for requirements for promotion.

- Formal requirements, especially for promotion to full professor, became more rigorous.

- Indicators of professional and scholarly achievement required for continued appointment and promotion were made more explicit.

- Weak or ambiguous language was revised or dropped.

- Greater emphasis was placed on research with weighting of different types more clearly defined.

- New types of professional expertise, scholarship, and learning were better taken into account.

The sidebar summarizes interviews with library administrators and selected candidates who have recently gone through the promotion and continued appointment process using the new document. Those interviewed largely saw the changes as evolutionary rather than revolutionary. Yet, they were in full agreement that the new version more clearly communicated to everyone what was expected, and why. This, in turn, provided 
a sound framework for candidates to plan their professional advancement and for committee members, supervisors, and administrators to give useful advice and make more fully informed judgments.

Although the process had been initiated to comply with a directive from the provost to review an existing policy, the revision actually "raised the bar" in two dimensions. One was foreseen from the start: the revised rules clarified requirements and more closely aligned institutional expectations of library faculty with those for academic faculty. The other dimension unfolded in the course of research, deliberation, and discussion: while building on past strengths, the revisions made to the document elevated to the foreground a set of underlying principles and obligations for Virginia Tech librarians.

As the document was ratified by unanimous vote of the LFA, so was the principle that supervisors and senior faculty should assume an active mentoring role. So was the idea that all parties stood to benefit by using the standards as the framework for ongoing conversations about scholarship and professional development. So was the goal that rich narratives that highlight individual strengths, not cookie-cutter formalities, should continue to inform and drive the review process.

\section{Conclusion and Implications}

As a technical example of drafting and consensus-building, the approaches outlined in this article and the resulting Virginia Tech Promotion and Continued Appointment document may be just as useful to other libraries as the comparative analysis of documents from selected institutions proved on this campus. However, the real significance for other libraries seeking to "raise the bar" with regard to their own retention, promotion, and tenure standards may be as a way of looking at policy change and its legacy.
Upon reflection, the revision articulated and reinforced at least three possible perspectives on the policy's significance and the shifts in organizational culture. Each perspective raises different questions, addresses different kinds of evidence, and points to different implications for building on what has been achieved so far. None presents a complete picture, yet each illuminates a part of it.

- Was the shift toward mentoring and mutuality the result of the process of revision and adoption - with its intensive schedule, its survey of faculty opinion, its analyses of policies at benchmark universities, and its regular public discussions? If so, perhaps the culture will regress as memories fade and the lesson may be that consciousness-raising activities will be necessary until faculty internalize new norms.

- Was the shift the result of the contents of the revision-with their greater references to university-wide norms, their inclusion of values and assumption, their flexible criteria, and their naturalistic organization? If so, perhaps formal language and library culture will become mutually reinforcing, and the lesson may be that well-drafted governance policies can create more than paperwork wrapped in red tape.

- Was the shift the result of outside circumstances - with the effects of the personnel changes, committee makeup, and recent library and university-wide strategic planning initiatives that took place? If so, perhaps the revised policy was nearly as much a consequence as a cause, and the lesson may be that progress can depend on opportunities of the moment.

These perspectives on the impact and interaction of the processes, content, and circumstances surrounding policy change are more than retrospective musings about a lone Virginia Tech initiative. 
Taken together, they provide a basis for any library to look at its local situation, its internal and external constituencies, and its values and goals.

\section{Sidebar: What Happened?}

When the revised Virginia Tech Libraries' promotion and continued appointment document had been in place for two years, the authors sought firsthand impressions of the effects of the new document. They interviewed library administrators and selected library faculty. Interviews were done individually, using a semistructured approach with a preset list of questions that focused on the effects the document had on their own and others' behavior. Interviewees were asked to reflect on their experiences under the old and new rules and to comment on the document as an expression of university and library expectations.

Dean of Libraries Eileen Hitchingham and Associate Dean Don Kenney emphasized the greater clarity of the revised document, both procedurally and, especially, in its explicit articulation of professional growth and mentoring as library goals. They noted that the substance of the processes-committee review of heavily narrative evidence of one's librarianship, scholarship, and service-was not substantially changed from norms and customs dating at least as far back as 1989 .

Hitchingham noted the importance of greater clarity to her in making the case for library faculty to the university-level committee on promotion and continued appointment and other decision makers unfamiliar with the library culture and internal function. "It helps me show how the library answers their questions, such as: What do you value? What's important? What are some examples of it?"

Kenney, who ex officio has chaired the library P\&CA Committee since 1993, noted the importance of greater clarity about ends and means to focus committee deliberations and recommendations on helping rising library faculty to achieve their professional and scholarly goals.

Both said they believe the revision made it easier for candidates, committees, and administrators to know what was expected of them at the different stages of the retention, promotion, and continued appointment processes. "Mechanically, it's made such an improvement," Hitchingham said. "It's made a stressful process [of structuring one's dossier] much more straightforward."

On the other hand, both noted, the revised procedures also impose an obligation on candidates to "tell their own stories" persuasively - to articulate their professional goals, relate them to library and university goals, give accounts of their achievements, and substantiate them through meaningful letters of reference and other documents.

They say that values and assumptions language added to the policy encourages the library P\&CA Committee to tell a correlatively rich "story" in its recommendations to the faculty member, to the dean and external audiences, and, they hoped, to the candidates' supervisors. Neither candidates nor committees can hide behind formal, one-size-fits-all checklists of performance.

The authors identified several librarians who had previously gone through the old rules for second- and fourth-year retention review, promotion, and/or continued appointment and had lately "gone up" under the revised rules. Two agreed to be interviewed.

Professors A and B praised the new document as a substantial clarification of previous policy at Virginia Tech. Each put the greater explicitness of a local document in a larger context: A noted that promotion and tenure dossiers for librar- 
ians in a previous position were "guess as guess can." B said "the review of what others are doing nationally [that went into the drafting of the new document] inspires confidence in the process."

Continuity with previous practices allowed them to rework their previous dossiers for the library P\&CA process with little difficulty. They added that they were concerned that newer employees, especially those new to librarianship in a research university, may need more than the document to understand fully what is expected of them. Each noted that the library should offer more thorough orientation about university-wide expectations for faculty. Both suggested enhancements to P\&CA appendices to promote more consistent and effective dossiers.

The more discursive approach to accounting for one's work in the revised policy may be a mixed blessing. On the one hand, it "gives you some latitude depending on the nature of one's work," A said, "and it lays it out a little more clearly." On the other hand, said B, "People tend to read into it what they want."

The revision does not change a potential underlying source of inconsistency in how candidates are treated, B added. "Rigor comes not only from the document, but also from the committee's interpretation of it." She also expressed concern that distinctive performance by one candidate may skew committee perceptions of the rest of the candidate pool. Moreover, eligibility and election to serve on the P\&CA Committee were not changed, so the possibilities remain that members themselves may not be familiar with the latest trends in librarianship, may not actively engage in professional development or scholarship, or may hold lower ranks than candidates whose cases they are judging.

Conversely, A claimed her recent experiences supported the library administration's faith in the process. "It works both ways-keeping people and getting rid of people, as well as helping them do better."

A and B are also departmental supervisors. They noted that the revised document is a useful reference point for evaluating and fostering faculty in their areas. However, both added, related policies for faculty annual evaluations and posttenure review need to be rewritten - and then administered-to mesh with the letter and spirit of the revised P\&CA policy. Customarily, the personnel policies have been treated separately, with their own statements of expectations of faculty. A and B said these different rules and procedures have at times impeded supervisors' ability to guide and correct their subordinates.

\section{Notes}

1. For an overview and analysis, see Betsy Park and Robert Riggs, "Tenure and Promotion - A Study of Practices by Institutional Type," Journal of Academic Librarianship 19 (May 1993): 72-77; Virginia Vesper and Gloria Kelley, Criteria for Promotion and Tenure for Academic Librarians: Clip Note \#26 (Chicago: ALA, 1997); Carol W. Cubberly, Tenure and Promotion for Academic Librarians: A Guidebook with Advice and Vignettes (Jefferson, N.C.: McFarland, 1996); Shannon Cary, "Faculty Rank, Status, and Tenure for Librarians: Current Trends," College E Research Libraries News 62 (May 2001): 510-11, 520; Pat Weaver-Meyers, "Conflict Resolution: A Case Study about Academic Librarians and Faculty Status," College E Research Libraries 63 (Jan. 2002): 25-33; Diane. Ruess, "Faculty and Professional Appointments of Academic Librarians: Expanding the Options for Choice," portal: Libraries and the Academy (Jan. 2004) 75-84.

2. The complete text of the new document developed at the University Libraries at Virginia Tech may be found online at http:/filebox.vt.edu/users/lener/PCA. The original version of the procedures also is provided there for comparative purposes. In addition, one of the working drafts is included because it features details of markup and comments about specific changes. 
3. Virginia Polytechnic Institute and State University, Office of the Provost, Faculty Handbook (Blacksburg, Va.: Virginia Tech). Available online at http://www.provost.vt.edu/web_pages/faculty_handbook.pdf.

4. 는 Strategic Plan. (Blacksburg, Va.: Virginia Tech, 2001). Available online at http://www. unirel.vt.edu/stratplan/.

5. - Office of the Provost, Memorandum, "Recommendations from the Ad Hoc Committee on Promotion and Tenure," Jan. 7, 2002.

6. Association of College and Research Libraries, Academic Status Committee, "Model Statement of Criteria and Procedures for Appointment, Promotion in Academic Rank, and Tenure for College and University Librarians," College and Research Libraries News 48 (May 1987): 247-54. Available online at http://www.ala.org/ala/acrl/acrlstandards/standardsguidelines.htm.

7. For a representative example of the data gathered, see appendix II. For the complete comparative analysis spreadsheet of the SCHEV and next-tier NSF universities, see http://filebox. vt.edu/users/lener/PCA. See also National Science Foundation, Academic Research Development Expenditures: Fiscal Year 2000 (NSF 02-308) (Arlington, Va.: NSF, Feb. 2002). Available online at http://www.nsf.gov/sbe/srs/nsf02308/sectb.htm; Virginia Polytechnic Institute and State University, Office of Institutional Research and Planning Analysis, "Virginia Tech's Peer Institutions." Available online at http://www.irpa.vt.edu/peers.htm.

8. Association of Research Libraries, ARL Statistics, Interactive Edition. Available online at http://fisher.lib.virginia.edu/arl/index.html.

9. Ibid.

10. For a discussion of the roles of librarians and the faculty reward system, see Association of College and Research Libraries, Task Force on Institutional Priorities and Faculty Rewards, Academic Librarianship and the Redefining Scholarship Project (Chicago: ACRL, 1998). Available online at http://www.ala.org/ala/acrl/acrlpubs/whitepapers/whitepapersreports.htm. 


\section{APPENDIX I \\ Library Faculty Survey Regarding the Procedures on Promotion and Continued Appointment}

\section{Section 1. Report Recommendations}

Below are the three major recommendations of the Ad Hoc Committee on Promotion and Tenure that we have been specifically asked to address. Please give us your thoughts on how these relate to our current documentation and what you think should be changed to better meet them.

\section{Recommendation \#1}

Promotion and tenure expectations and standards concerning research productivity must reflect Virginia Tech's goal of becoming a Top 30 research university. Elements and outcomes of the research enterprise valued by Virginia Tech should be identified by each department, operationalized within the context of the department's mission and structure, and reflected in its guidelines for promotion and tenure.

Your comments on implementing the above recommendation:

\section{Recommendation \#2}

Processes must be in place to ensure that promotion and tenure expectations and standards are communicated to faculty fairly and effectively. Guidelines for promotion and tenure must explicitly delineate appropriate measures or indicators of successful outcomes with respect to research, teaching, and outreach.

Your comments on implementing the above recommendation:

\section{Recommendation \#3}

Standards for promotion of faculty from associate professor to professor must be unequivocally upheld and should require evidence of genuine excellence in two areas, one of which is research and scholarship.

Your comments on implementing the above recommendation:

\section{Section 2. Other Considerations}

In addition to the specific recommendations of the report, we now have a chance to review and possibly modify or update other sections of the document. For each of the following categories, please consider the following general questions: 
- What do you consider strengths or aspects of the current policy that you want to see us keep?

- What do you consider weaknesses or changes that you would like to see made?

- Is there any language in the policy that you find unclear or ambiguous?

Review Process and Timetable

Criteria for Review-4.2.1 Professional Responsibilities

Criteria for Review -4.2.2 Research and Scholarly Activities

Criteria for Review - 4.2.3 University and Library Service

Criteria for Review - 4.2.4 Professional Contributions and Services Activities

Library Strategic Plan (http://www.lib.vt.edu/info/stratplan/overview.html)

Other

\section{Section 3. Statistical Information (Optional)}

Your current rank:
$\square$ Instructor
Assistant Professor
Associate Professor
$\square$ Professor

Years of service at Virginia Tech:
$\square>2$
口 2-5
口 6-10
口 11-15
口 15-20
$\square 20+$

Years of professional experience:
$\square>2$
$\square 2-5$
口 6-10
口 11-15
口 15-20
20+

Have you ever served on the library's P\&CA Committee?

$\square$ Yes $\square$ No 


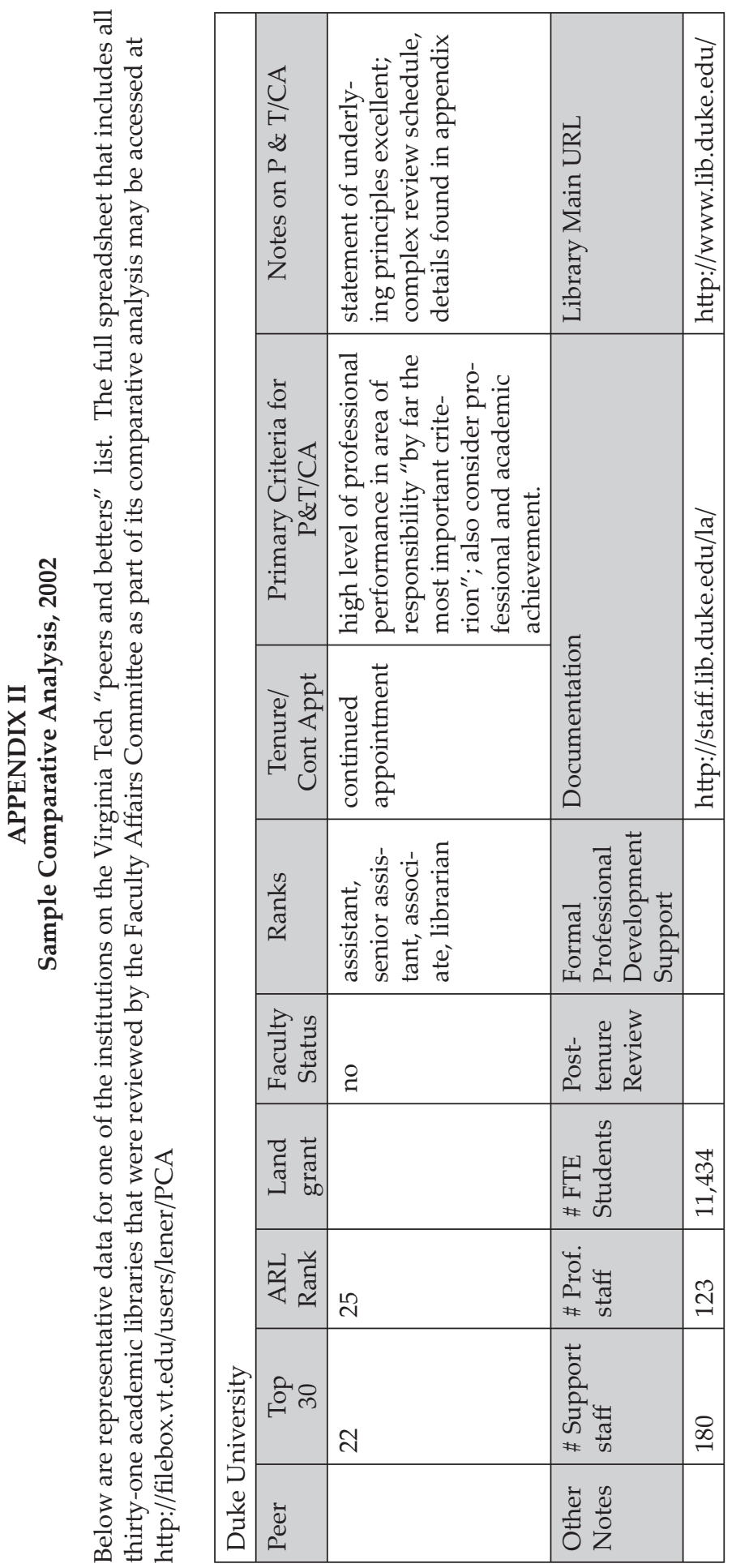

